\title{
Optimization of Wear Performance of Electroless Ni-B Coating Under Lubrication
}

\author{
Santanu Duari ${ }^{1,2}$, Arkadeb Mukhopadhyay $^{2}$, Tapan Kumar Barman ${ }^{2}$ \\ and Prasanta Sahoo ${ }^{2 *}$ \\ ${ }^{1}$ Techno India College of Technology, Rajarhat, Kolkata 700156, India \\ ${ }^{2}$ Deparment of Mechanical Engineering, Jadavpur University, Kolkata 700032, India \\ ${ }^{*}$ Corresponding author (Email: psjume@gmail.com)
}

Keywords: Electroless Ni-B coating; Wear; Lubrication; Taguchi method; Optimization

\begin{abstract}
This paper presents an experimental study on tribological behavior of electroless Ni-B coating under lubricated condition based on Taguchi's method. Mild steel specimens are used as the substrate material for the deposition of Ni-B coating and the thickness of the deposits is found to be around $35 \mu \mathrm{m}$. Based on Taguchi's $\mathrm{L}_{27}$ orthogonal array of experiments, the wear tests are done on a pin-on-disc type tribotester This experiment is carried out by utilizing the combination of process parameters of the tribotester like normal load, sliding speed and duration of sliding. The analysis of the experimental data is carried out with the help of MINITAB ${ }^{\circledR}$ software package. It is seen that the normal load is the most significant factor followed by sliding time at $99 \%$ confidence level. The surface morphology, composition and compound analysis of the coatings are done by means of scanning electron microscope, energy dispersed X-ray micro-analyzer and X-ray diffraction analyzer respectively. Finally, a confirmation test is carried out to validate the analysis.
\end{abstract}

\section{Introduction}

Electroless nickel (EN) plating is an innovative method of surface coating technology which has been well accepted globally by researchers. This revolutionary method of coating does not require the use of electricity. In the middle of the twentieth century, electroless Ni-P coating [1] was first developed by Brenner and Riddell [2,3] in 1946 to meet the challenging needs of a variety of industrial applications. Since then this coating has quickly developed to become a mature subject of research. Due to its excellent mechanical, electrical, physical, corrosion, hardness, friction and wear resistance properties [3], it has a wide range of industrial applications. It is also noted that $\mathrm{Ni}-\mathrm{B}$ coatings have high hardness and superior wear resistance characteristics [4-8]. It may be applied on irregular and intricate shapes of geometries due to its smooth and uniform deposition over the substrate. Electroless plating is an autocatalytic process where the substrate develops a potential when it is dipped in electroless solution called bath that contains a source of metallic ions, reducing agent, complexing agent, stabilizer and other components operating in a specific metal ion concentration, temperature, and $\mathrm{pH}$ ranges.

Invention of EN coating attracted many researchers in the field of tribological to develop and exploit the properties of this plating method. A study of wear of electroless Ni-B coating reveals that the coating in its as-deposited state exhibits high rates of wear. It was postulated that the unique high lubricity and high heat-tolerant properties of boron could provide solutions to many surfaceengineering challenges. It was observed that wear resistance increases with an increase of boron content in the coating. Mechanical and tribological properties of the coatings can further be improved by incorporating heat treatment. Very high heat treatment results in a decrease in the wear resistance due to grain coarsening and softening of the coatings due to conglomeration of $\mathrm{Ni}_{3} \mathrm{~B}$ particles [6]. But highest hardness may be achieved if the coating is heat treated in between $350^{\circ} \mathrm{C}$ to $450^{\circ} \mathrm{C}$ for 1 hour [9]. It is seen that under dry (non-lubricated) condition, adhesion and abrasion wear mechanisms are predominant in the causing the failure of these coatings [10]. 
In the present study, mild steel (AISI 1040) is taken as the substrate material for deposition of Ni-B coatings. Then heat treatment (annealing) of the coated specimens is done at $350^{\circ} \mathrm{C}$ for 1 hour. Wear characteristic is studied in a tribotester under lubricated condition by varying three process parameters viz. normal load, sliding speed and sliding time. Based on the degrees of freedom of the experiment, Taguchi's $\mathrm{L}_{27}$ orthogonal array design is used to find out the optimum combination of tribo-testing parameters. Analysis of microstructure, composition, phase transformation and wear are discussed from the results of scanning electron microscope (SEM), energy dispersed x-ray micro-analyzer (EDX), and x-ray diffraction analyzer (XRD) respectively. A confirmation test is finally done to validate the experimental results.

\section{Taguchi Method}

Taguchi analysis is a powerful tool for design of high quality systems based on orthogonal array (OA) [11]. It is nothing but the shortest possible matrix of combinations in which all the parameters are varied simultaneously and their effects and performance interactions are studied. Taguchi method uses a statistical measure of performance called signal-to-noise $(\mathrm{S} / \mathrm{N})$ ratio (in decibels), which is logarithmic function of the desired output to serve as objective functions for optimization. The $\mathrm{S} / \mathrm{N}$ ratio considers both the mean and the variability into account. It is defined as the ratio of the mean (signal) to the standard deviation (noise). The ratio depends on the quality characteristics of the product/process to be optimized. The three categories of $\mathrm{S} / \mathrm{N}$ ratios are used: lower-the-better (LB), higher-the-better (HB) and nominal-the-best (NB), as follows:

$\mathrm{S} / \mathrm{N}$ ratio for LOWER - THE - BETTER (minimize),

$$
S / N_{S}=-10 \log \left(\frac{1}{n} \sum_{i=1}^{n} y_{i}^{2}\right)
$$

$\mathrm{S} / \mathrm{N}$ ratio for HIGHER - THE - BETTER (maximize),

$$
S / N_{L}=-10 \log \left(\frac{1}{n} \sum_{i=1}^{n} \frac{1}{y_{i}^{2}}\right)
$$

$\mathrm{S} / \mathrm{N}$ ratio for NOMINAL - THE - BEST,

$$
S / N_{T}=10 \log \left(\frac{\bar{y}^{2}}{s_{y}^{2}}\right)
$$

where $y$ is the observed data, $n$ is the number of observations, $\bar{y}$ is the average of the observed data and $s_{y}^{2}$ is the variance of $y$.

The parameter level combination that maximizes the appropriate $\mathrm{S} / \mathrm{N}$ ratio is the optimal setting. For wear, LB characteristic needs to be used. Furthermore, analysis of variance (ANOVA) [12] is performed to find the significant parameters and their interactions that affect the response. Finally, a confirmation test is carried out to verify the optimal process parameters obtained from the analysis.

\section{Experimental Details}

Coating deposition. Mild steel (AISI-1040) cylindrical specimens of size Ø6mm x 30mm are used as the substrate material for the deposition of the electroless Ni-B coating. For preparation of sample, some machining operations are used like turning, facing, parting and grinding. The samples are cleaned from foreign matter and corrosion products by wiping. For coating deposition the 
surfaces of the specimens are cleaned carefully using distilled water, etched with $50 \%$ hydrochloric acid (for $1 \mathrm{~min}$ ), rinsed in distilled water and methanol subsequently. Finally, the cleaned samples are activated in palladium chloride at $55^{\circ} \mathrm{C}$ temperature for a few seconds and placed in the electroless bath. Bath composition and operating conditions are displayed in Table 1. Deposition parameters are kept constant for each specimen so that the coating thickness remains constant. The deposition thickness is found to be around $35 \mu \mathrm{m}$. After the deposition, the samples are taken out of the bath and rinsed in distilled water. By using a box furnace the samples are heat treated (annealed at $350^{\circ} \mathrm{C}$ for $1 \mathrm{~h}$ ) individually followed by normal air cooling.

Table 1. Bath composition and operating conditions.

\begin{tabular}{llll}
\hline Bath composition & \multicolumn{3}{c}{ Operating condition } \\
\hline Nickel chloride & $20[\mathrm{~g} / \mathrm{L}]$ & $\mathrm{pH}$ & 12.5 \\
Sodium borohydride & $0.8[\mathrm{~g} / \mathrm{L}]$ & Time & $2 \mathrm{~h}$ \\
Ethylenediamine & $59[\mathrm{~g} / \mathrm{L}]$ & Deposition Temperature & $90 \pm 2\left[{ }^{\circ} \mathrm{C}\right]$ \\
Lead nitrate & $0.0145[\mathrm{~g} / \mathrm{L}]$ & Bath Vol. & $200[\mathrm{ml}]$ \\
Sodium hydroxide & $40[\mathrm{~g} / \mathrm{L}]$ & & \\
\hline
\end{tabular}

Design factors and response variables. The first target is to find out the design factor along with their levels. Here the tribological testing conditions for electroless Ni-B coating are selected from a thorough review of literature. The most important parameters that affect the wear characterisctics are seen to be normal load (L), sliding speed (S) and duration of sliding (T). Depending on the thickness of coating, the levels are also selected so that depth of wear should be less than deposition of thickness. Table 2 displays the main design factors along with their different levels.

Table 2. Design factors along with their levels.

\begin{tabular}{|c|c|c|c|c|}
\hline \multirow{2}{*}{ Design factors } & \multirow{2}{*}{ Unit } & \multicolumn{3}{|c|}{ Levels } \\
\hline & & 1 & 2 & 3 \\
\hline Load (L) & $\mathrm{N}$ & 10 & $20 *$ & 30 \\
\hline Speed (S) & RPM & 60 & $80 *$ & 100 \\
\hline Time $(\mathrm{T})$ & Min. & 5 & $10 *$ & 15 \\
\hline
\end{tabular}

Design of experiments. Based on Taguchi method, an OA provides the shortest possible matrix of combinations in which all the parameters are varied to consider their direct effect and interactions simultaneously. In this study, an $\mathrm{L}_{27} \mathrm{OA}$, which has 27 rows corresponding to the number of tests and 26 degrees of freedom (DOFs) with 13 columns at three levels, is chosen to fulfill the experiment. To check the DOFs in the experimental design, for the three level test, the three main factors take $6[3 \times(3-1)]$ DOFs. The DOF for three second-order interactions $(\mathrm{L} \times \mathrm{S}, \mathrm{L} \times \mathrm{T}, \mathrm{S} \times \mathrm{T})$ are $12[3 \times(3-1) \times(3-1)]$ and so the total DOFs required is 18 . As per Taguchi method, the total DOFs of selected OA must be greater than or equal to the total DOFs required for the experiment and hence the $\mathrm{L}_{27} \mathrm{OA}$ has been selected.

Wear tests. The wear tests are carried out by utilizing the combination of testing parameters (Table 2) of a pin-on-disc type tribotester (TR-20LE-CHM-400, Ducom, India) viz. normal load, sliding speed (rpm) and time of operation under lubricated condition. These tests are done at constant track diameter of $80 \mathrm{~mm}$ and at room $\left(36^{\circ} \mathrm{C}\right)$ temperature. The heat treated EN-coated specimen is fixed ( kept stationary) vertically by an attachment and the counterface disc rotates.

On application of load, this pin presses against the rotating disc of size $\phi 165 \times 8 \mathrm{~mm}$ made of hardened steel of EN31 grade. A 1:1 ratio-loading lever is used to apply the normal load on specimen by placing dead weights on a loading pan. The frictional force and depth of wear are measured by sensors. Fig. 1 shows the experimental set-up of pin-on-disc type tribotester. 


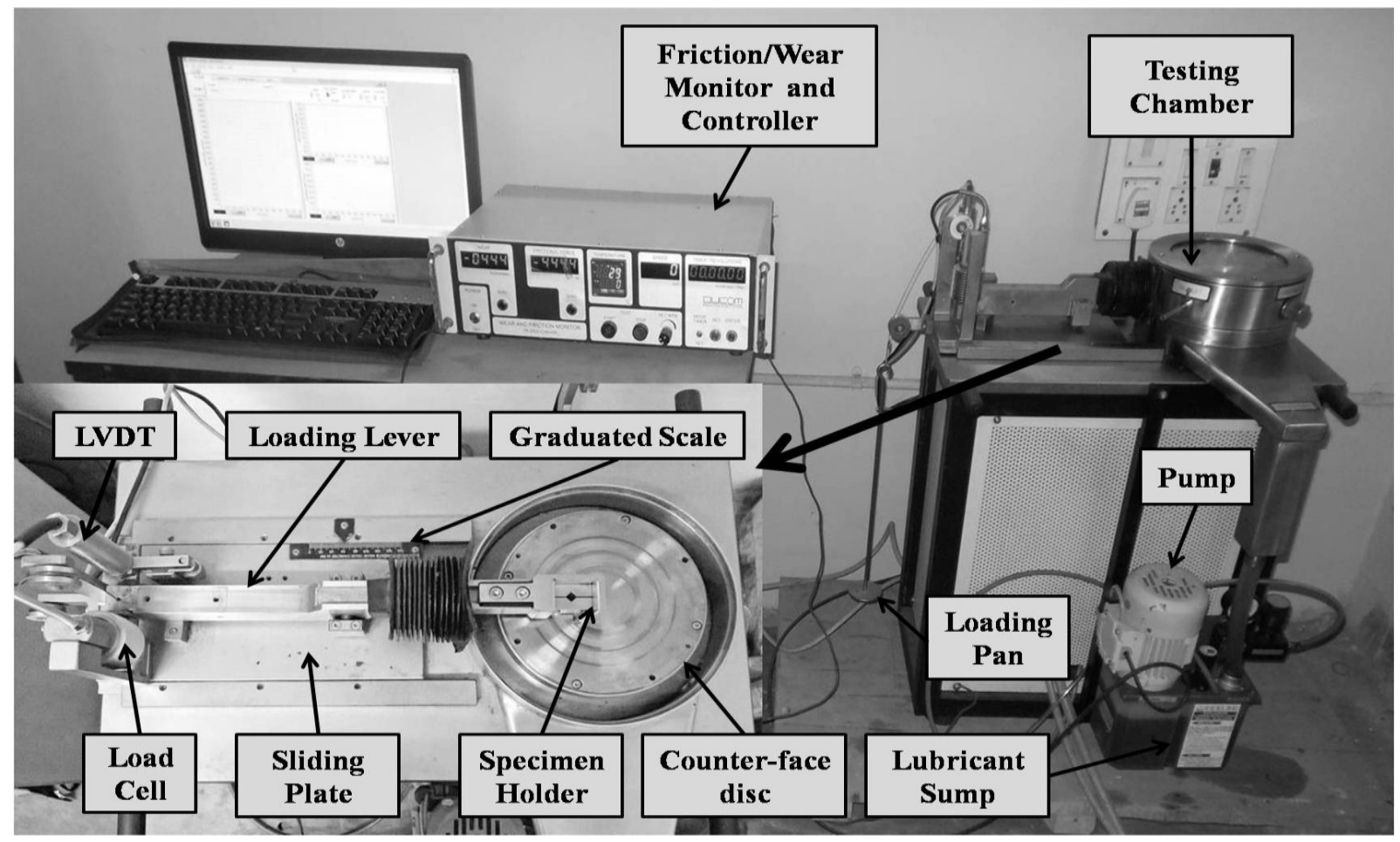

Fig. 1. Pin-on-disc type tribo - tester (experimental set-up).

Lubricant used. The lubricant used in this experiment is Servo PRIDE-40 engine oil, a product of Indian Oil. The characteristic of the lubricant oil is displayed in Table 3. The lubricant was fed at the contact between the specimen and the roller with the aid of a copper pipe, equipped with a valve for adjusting the feeding rate. Feeding of the lubricant was continuous and constant care is also taken for, at the start and end of the tests, so that the contact between roller and specimen surface is covered with a lubricant film.

Table 3. Properties of the lubricant.

\begin{tabular}{ll}
\hline Properties & Values \\
\hline Kin. Vis. cSt @ $100^{\circ} \mathrm{C}$ & $13-15$ \\
Viscosity Index, Min. & 90 \\
Flash point $(\mathrm{COC}),{ }^{\circ} \mathrm{C}$ Min. & 220 \\
Pour Point, ${ }^{\circ} \mathrm{C} \mathrm{Max}$. & $(-) 6$ \\
TBN mg KOH/gm & $9.5-12.5$ \\
\hline
\end{tabular}

Surface morphology and composition study. These studies have been done to analyze the microstructure (from SEM, FEI Quanta 200), composition (from EDX, FEI Quanta 200) and compound (from XRD, Rigaku, Miniflex) of the deposited coating before and after annealing at $350^{\circ} \mathrm{C}$ in order to see the effect of heat treatment temperatures.

\section{Results and Discussion}

The lubricated sliding wear tests are carried out on a pin - on - disc tribo - tester. The results of the tests are shown in Table 4. The experiments are carried out serially as per the combinations given in Taguchi's $\mathrm{L}_{27}$ orthogonal array. To carry out the optimization of tribo - testing parameters for minimum wear depth under lubrication, $\mathrm{S} / \mathrm{N}$ ratios are calculated using lower - the - better quality characteristics from Eq. 1. The corresponding $\mathrm{S} / \mathrm{N}$ ratios of wear depth are also given in Table 4. Further analysis of the experimental data obtained from the tribological tests is carried out subsequently in the present work. 
Table 4. Experimental results for wear tests.

\begin{tabular}{lll}
\hline Exp. No. & Wear Depth $(\boldsymbol{\mu m})$ & S/N Ratio $(\mathbf{d B})$ \\
\hline 1 & 3.579 & -11.0752 \\
2 & 4.412 & -12.8927 \\
3 & 4.996 & -13.9724 \\
4 & 4.148 & -12.3568 \\
5 & 5.04 & -14.0486 \\
6 & 6.24 & -15.9037 \\
7 & 3.98 & -11.9977 \\
8 & 4.897 & -13.7986 \\
9 & 5.357 & -14.5784 \\
10 & 5.227 & -14.3651 \\
11 & 6.471 & -16.2194 \\
12 & 7.22 & -17.1707 \\
13 & 5.5 & -14.8073 \\
14 & 6.557 & -16.3341 \\
15 & 7.463 & -17.4583 \\
16 & 5.646 & -15.0348 \\
17 & 6.79 & -16.6374 \\
18 & 7.757 & -17.7939 \\
19 & 7.857 & -17.9051 \\
20 & 9.814 & -19.8369 \\
21 & 11.492 & -21.2079 \\
22 & 7.795 & -17.8363 \\
23 & 9.591 & -19.6373 \\
24 & 10.985 & -20.816 \\
25 & 7.684 & -17.7117 \\
26 & 9.37 & -19.4348 \\
27 & 10.917 & -20.7621 \\
\hline
\end{tabular}

Analysis of $\mathbf{S} / \mathbf{N}$ ratio. The analysis of signal to noise $(\mathrm{S} / \mathrm{N})$ ratio is done using the LB (lower-the better) criterion with Taguchi method. The response table for this analysis is shown in Table 5. The corresponding main effects and interaction plots between the testing parameters are also shown in Fig. 2 and Fig. 3 respectively. In the main effects plot for a particular parameter, if a line has the highest inclination then the parameters is most significant. It is very much clear both from the response table (Table 5) and from the plots that parameter L (normal load) is the most significant parameter amongst the other parameters. From interaction plots (Fig. 3), it can be seen that there is high interaction between the parameters L (normal load) and T (sliding time), a moderate interaction between the parameters L (normal load) and S (speed) and almost no interaction between S (speed) and $\mathrm{T}$ (time). The optimal process parameter combination for wear is found to be L1S1T1 (lowest level of all parameters).

Table 5. Response table for $\mathrm{S} / \mathrm{N}$ ratio.

\begin{tabular}{llll}
\hline Level & L & S & T \\
\hline 1 & -13.4 & -16.07 & -14.79 \\
2 & -16.2 & -16.58 & -16.54 \\
3 & -19.46 & -16.42 & -17.74 \\
Delta & 6.06 & 0.51 & 2.95 \\
Rank & 1 & 3 & 2 \\
\hline \multicolumn{5}{r}{}
\end{tabular}

Analysis of variance (ANOVA). ANOVA is a statistical technique to find out the significance of individual process parameters and their interactions on the system response under consideration and also their respective percentages of contribution [11-12]. This is done by separating the total 
variability of the $\mathrm{S} / \mathrm{N}$ ratio. Minitab [13] is used for the same and the analysis result is shown in Table 6. It is seen that at $99 \%$ confidence level the most significant parameter is normal load (L) followed by time $(\mathrm{T})$. Some significance of the interaction of parameters is also seen.

Table 6. Results of ANOVA for wear depth.

\begin{tabular}{lcllll}
\hline $\begin{array}{l}\text { Source of } \\
\text { variation }\end{array}$ & DOF & $\begin{array}{l}\text { Sum of } \\
\text { squares }\end{array}$ & $\begin{array}{l}\text { Mean } \\
\text { Square }\end{array}$ & F-ratio & Contribution \% \\
\hline $\mathrm{L}$ & 2 & 104.2323 & 52.1162 & $1621.71^{*}$ & 78.312 \\
$\mathrm{~S}$ & 2 & 0.2846 & 0.1423 & 4.43 & 0.214 \\
$\mathrm{~T}$ & 2 & 24.6028 & 12.3014 & $382.79^{*}$ & 18.485 \\
$\mathrm{~L}^{*} \mathrm{~S}$ & 4 & 1.2252 & 0.3063 & $9.53^{*}$ & 0.921 \\
$\mathrm{~L}^{*} \mathrm{~T}$ & 4 & 2.4551 & 0.6138 & $19.1^{*}$ & 1.845 \\
$\mathrm{~S} * \mathrm{~T}$ & 4 & 0.0408 & 0.0102 & 0.32 & 0.031 \\
Error & 8 & 0.2571 & 0.0321 & & 0.193 \\
Total & 26 & 133.098 & & 100 \\
\hline
\end{tabular}

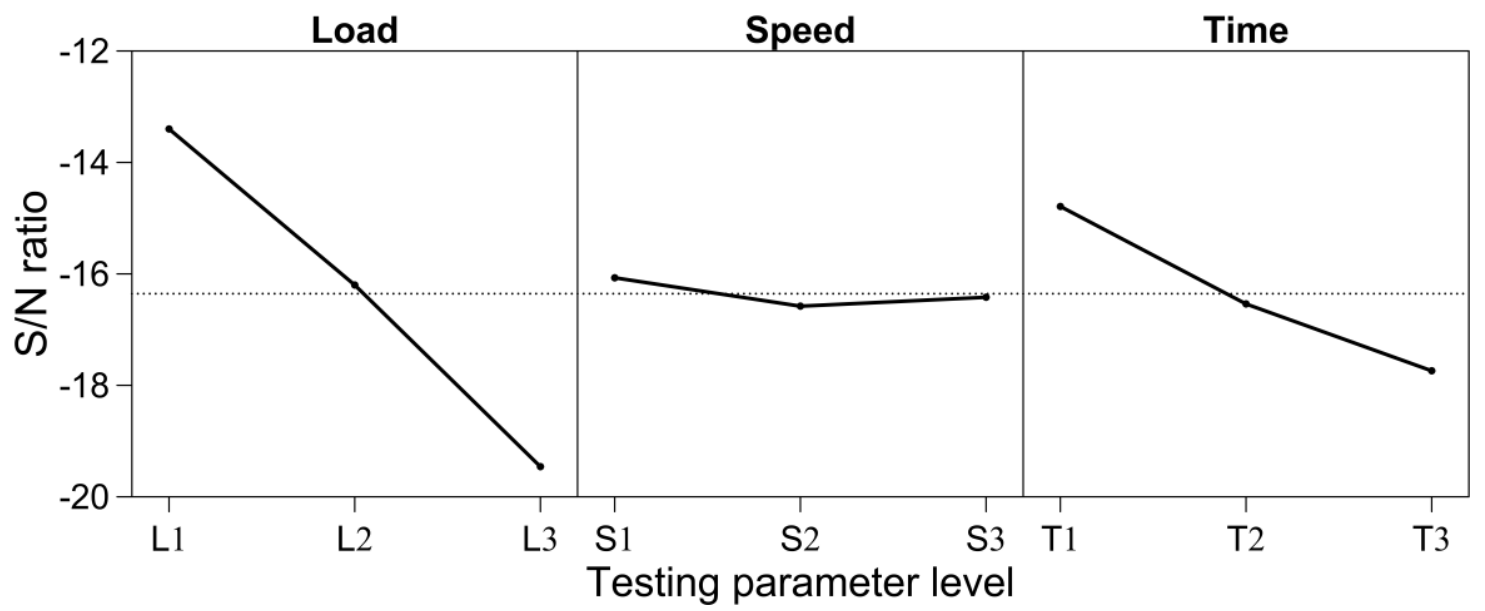

Fig. 2. Main effects plot for $\mathrm{S} / \mathrm{N}$ ratio.

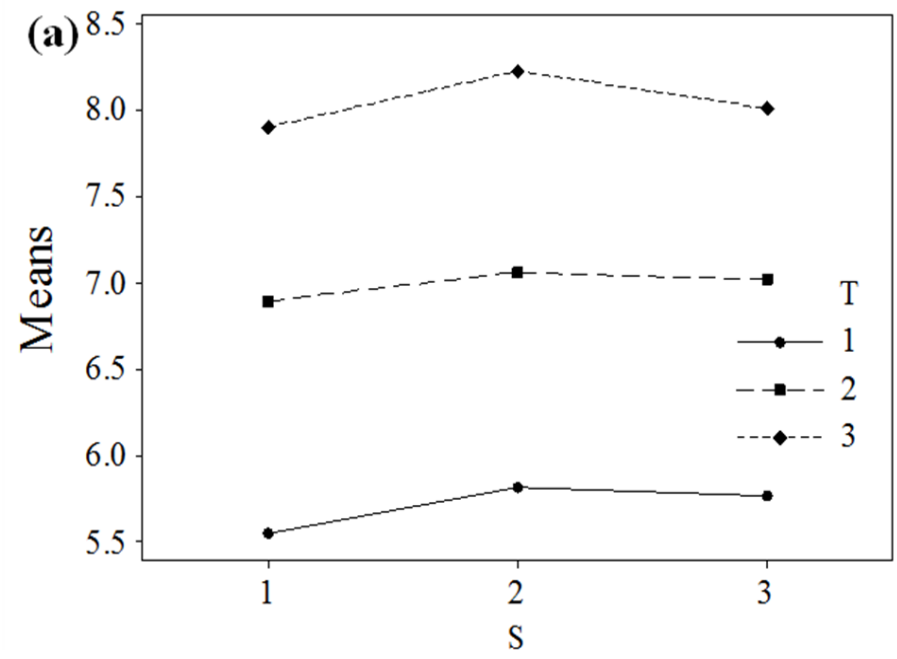



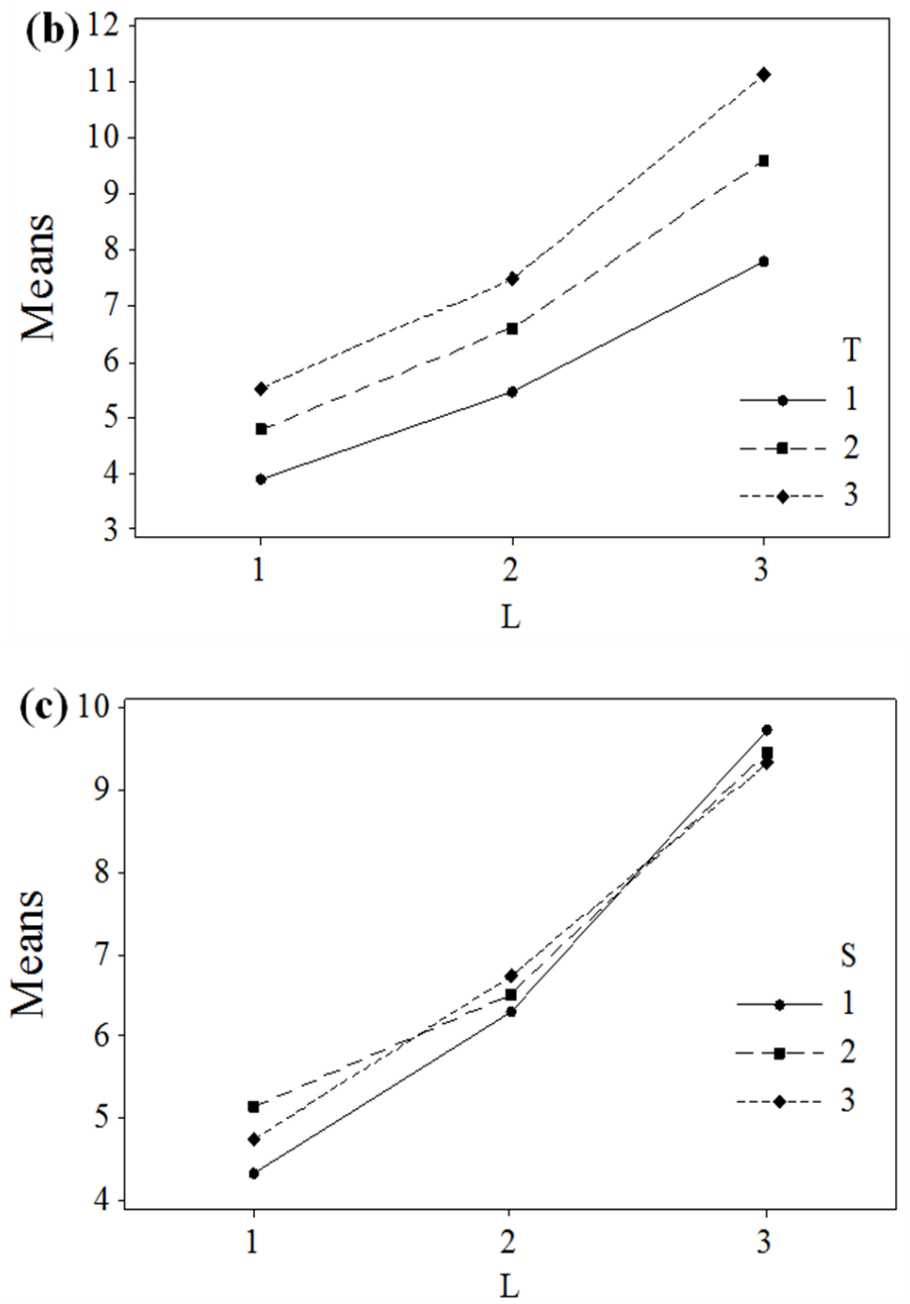

Fig. 3. Interaction plot between (a) Load and Speed (b) Load and Time (c) Speed and Time.

Surface morphology, wear mechanism, composition and phase transformation. Fig. 4(a) ensures the coating thickness around the substrate through SEM micrograph. SEM images of electroless Ni-B deposit for as deposited and after heat treatment are shown in Fig. 4(b) and Fig. 4(c) respectively. From the study of SEM micrographs of as deposited surface it is seen that there are many tiny nodulated particles. The surface is quite smooth and of less porosity without any visible surface damage. This analysis indicates that the as-deposited Ni-B film is a mixture of amorphous and microcrystalline phases. Upon heat treatment of the coating, microstructural modifications take place. During modification, a crystal growth process takes and thus heat treatment results in a mixture of relatively coarse-grained structure. The growth of the nodulated structures on heat treatment is clearly visible in Fig. 4(c).

Fig. 4(d) shows the SEM micrograph of the worn surface of a Ni-B coated sample after performing experiment on it. From the micrograph it is clearly seen that the coating has suffered very less wear. Longitudinal grooves along the direction of sliding can be observed. This is a clear indication of mild abrasive wear being the predominant mechanism of failure of the coating. The hardness value is enhanced on heat treatment which in turn increases the plastic resistance of the coating [6] preventing adhesion between the coated pins and the counterface disc. The lubricant film also prevents adhesion of the test specimen and the counterface material. 

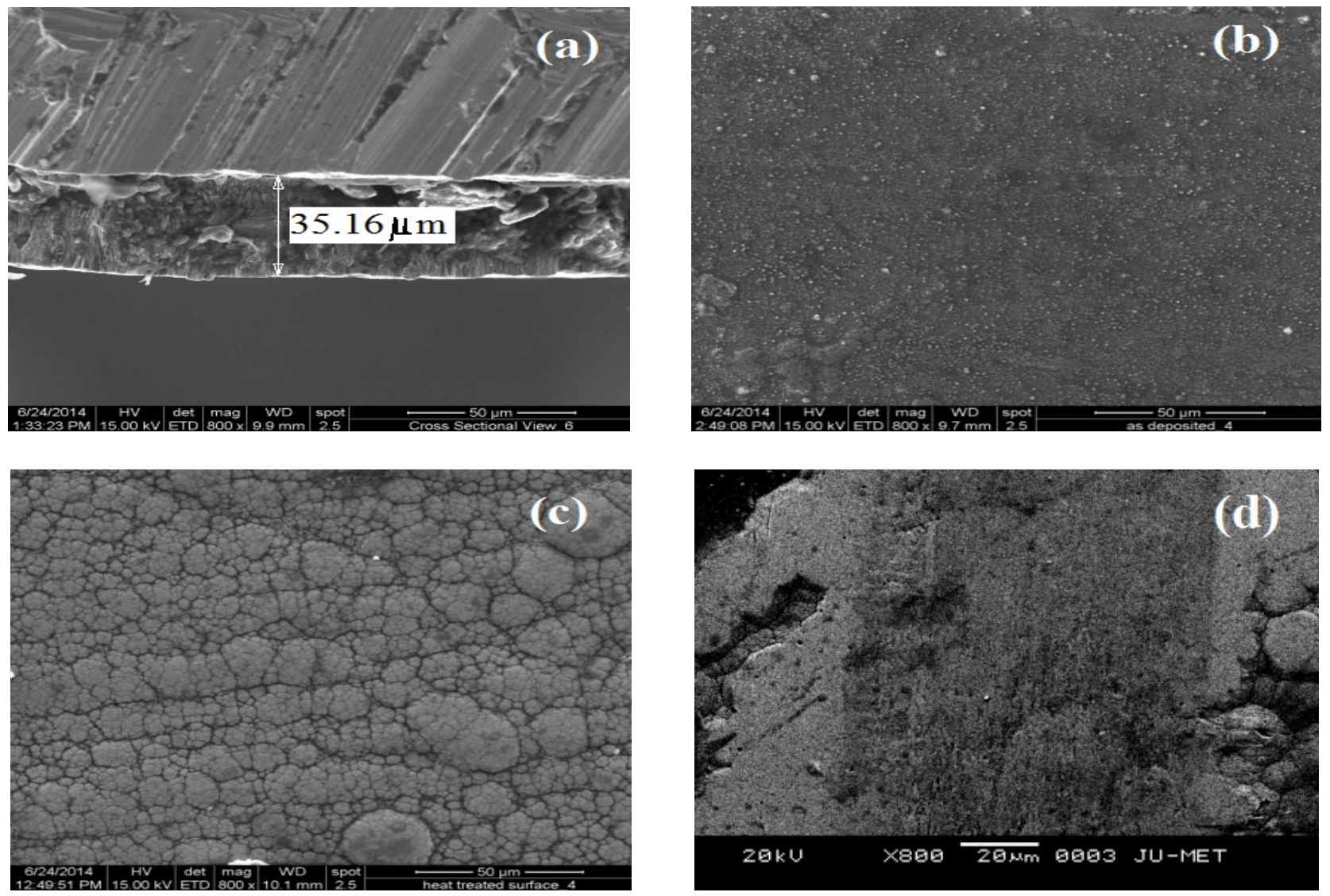

Fig.4. SEM micrographs of electroless Ni-B deposit in (a) cross-sectional (b) as-deposited and (c) heat treated $(d)$ worn surface of tested sample.

EDX analysis is done to find out the percentage content of nickel and boron by weight in the deposits. The EDX spectrum confirms the presence of boron and is seen to be in the range of 5.42 to $7.51 \%$ by weight while the rest is mostly nickel. EDX patterns of a Ni-B coated specimen after heat treatment is shown in Fig.5. XRD analysis confirms that coating is amorphous in as-plated condition and so a broad peak is identified. But on heat treatment, the deposits crystallize and precipitation of crystalline nickel and its borides $\left(\mathrm{Ni}_{2} \mathrm{~B}\right.$ and $\left.\mathrm{Ni}_{3} \mathrm{~B}\right)$ is seen to take place. Fig. $6(\mathrm{a})$ and 6(b) represent XRD plots for as deposited and heat treated condition respectively.

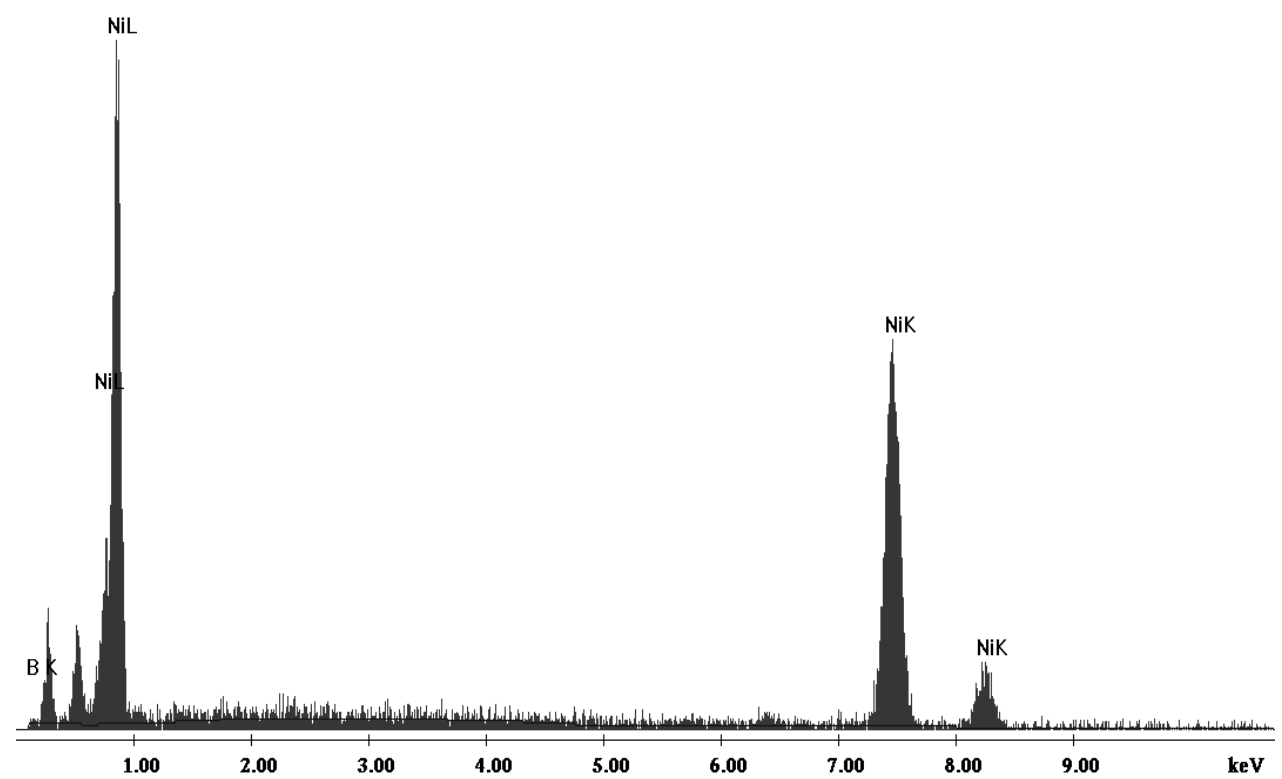

Fig. 5. EDX spectrum of Ni-B coated sample. 

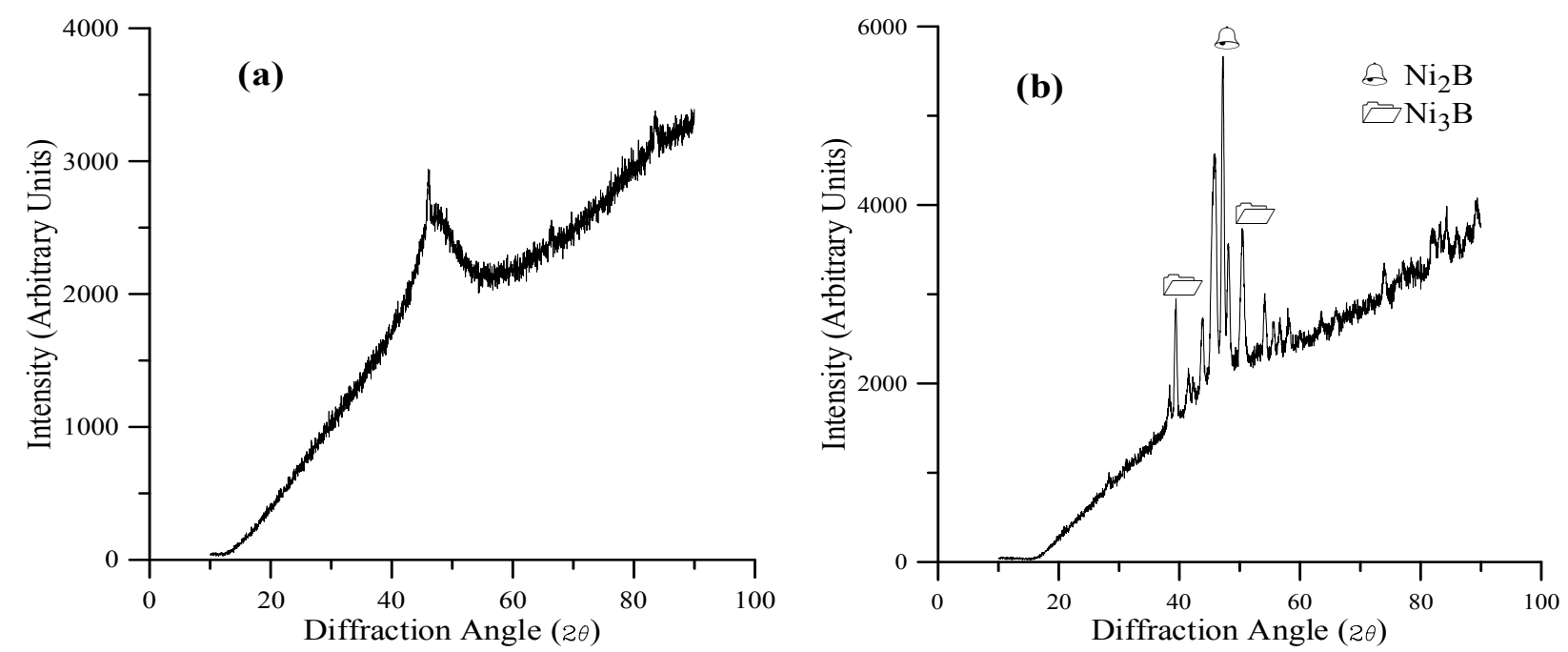

Fig.6. XRD patterns of electroless Ni-B deposit in (a) as-deposited and (b) heat treated sample.

Confirmation test. The last step of Taguchi's method is the validation of the optimization results predicted with experimentally obtained results. It is necessary to verify the test results in order to evaluate the accuracy of the analysis. The predicted $\mathrm{S} / \mathrm{N}$ ratio can be calculated as:

$$
\eta=\eta_{m}+\sum_{i=1}^{o}\left(\eta_{i}-\eta_{m}\right)
$$

where $\eta_{m}$ is the mean $\mathrm{S} / \mathrm{N}$ ratio, $\eta_{i}$ is the mean $\mathrm{S} / \mathrm{N}$ ratio at the optimal level of a process parameter and $o$ is the number of parameters affecting the system response. Result of confirmation test is shown in Table 7. Here, improvement of $\mathrm{S} / \mathrm{N}$ ratio from initial to optimal level is $-5.2589 \mathrm{~dB}$ (32.2\%). So it is a highly significant improvement. The predicted $\mathrm{S} / \mathrm{N}$ ratio and the experimentally obtained are in agreement with each other. This validates the gainful use of Taguchi's method and its significance in obtaining the optimum tribological behavior of electroless Ni-B coating under lubricated condition. Hence, Taguchi's method is successfully applied to obtain minimized wear of the deposits under the influence of a lubricant.

Table 7. Results of confirmation test.

\begin{tabular}{llll}
\hline & \multirow{2}{*}{ Initial Parameter } & \multicolumn{2}{l}{ Optimal Parameter } \\
\cline { 3 - 4 } & & Predicted & Experimental \\
\hline Level & L2S2T2 & L1S1T1 & L1S1T1 \\
Wear $[\mu \mathrm{m}]$ & 6.557 & & 3.579 \\
$\mathrm{~S} / \mathrm{N}$ ratio $[\mathrm{dB}]$ & -16.3341 & -11.55 & -11.0752 \\
& Improvement of S/N ratio $=-5.2589 \mathrm{~dB}$ & \\
\hline
\end{tabular}

\section{Conclusion}

Taguchi's OA is used to optimize the wear performance of electroless Ni-B coated specimen under lubricated condition. From the Taguchi analysis, it is seen that the lowest level of sliding speed, normal load and sliding time is the optimum combination to get minimum wear characteristics in the specified test range. From ANOVA, it is seen that the most significant parameter at $99 \%$ confidence level is the applied normal load followed by sliding duration. SEM results indicate the nodular surface morphology of electroless Ni-B coating. Abrasive wear is found from SEM image of wear tested sample. EDX analysis confirms the presence of boron in the deposits and is found to be around 5.42 to $7.51 \%$ by weight while the remaining is mostly nickel. XRD results show that amorphous/nanocrystalline structure for as-coated condition and after heat treatment the structure changes to crystalline with two major boride constituents $\left(\mathrm{Ni}_{2} \mathrm{~B}\right.$ and $\left.\mathrm{Ni}_{3} \mathrm{~B}\right)$. Confirmation test results 
reveal the improvement in wear characteristics of $\mathrm{Ni}-\mathrm{B}$ coating obtained under lubrication from Taguchi's design of experiments and optimization method. An improvement of $32.2 \%$ in the S/N ratio is achieved at the optimal combination of test parameters compared to the initial combination of testing. The present work thus widens the scope of usage of electroless Ni-B coating under oil lubricated condition.

\section{Acknowledgement}

The authors gratefully acknowledge the partial financial support of University Grants Commission (UGC), Govt. of India through Major Research Project vide Ref. No. F No. 41-984/2012 (SR) dated 25.07.2012.

\section{References}

[1] P. Sahoo, S.K. Das, Tribology of electroless nickel coatings - A review, Materials and Design, 32 (2011) 1760-1775.

[2] A. Brenner, G.E. Riddell, Deposition of nickel and cobalt by chemical reduction, J. Res. Nat. Bur. Stand. 39 (1947) 385-395.

[3] W. Riedel, Electroless nickel plating, ASM International, 1997.

[4] Y. N. Bekish, S.K. Poznyak, L.S. Tsybulskaya, T.V. Gaevskaya, Electrodeposited Ni-B alloy coatings: Structure, corrosion resistance and mechanical properties, Electrochim. Acta. 55 (2010) 2223-2231.

[5] P. A. Vityaz', V.A. Kukareko, L.S. Tsybul'skaya, Y.N. Bekish, T.V. Gaevskaya, Structure and Tribological Behavior of Ni-B and Co-B Galvanic Coatings, J. Frict. Wear. 31 (2010) 113120.

[6] K. Krishnaveni, T. S. N. S. Narayanan, S. K. Seshadri, Electroless Ni-B coatings: preparation and evaluation of hardness and wear resistance, Surf. Coat. Technol. 190 (2005) 115- 121.

[7] T. S. N. S. Narayanan, K. Krishnaveni, S. K. Seshadri, Electroless Ni-P/Ni-B duplex coatings: preparation and evaluation of microhardness, wear and corrosion resistance, Mater. Chem. Phys. 82 (2003) 771-779.

[8] K. N. Srinivasan, R. Meenakshi, A. Santhi, P. R. Thangavelu, S. John, Studies on development of electroless Ni-B bath for corrosion resistance and wear resistance applications, Surface. Eng. 26 (2010) 153-158.

[9] M. Anik, E. Körpe, E. Şen, Effect of coating bath composition on the properties of electroless nickel-boron films, Surf. Coat. Technol. 202 (2008) 1718-1727.

[10] I. Baskaran, R. S. Kumar, T. S. N. S. Narayanan, Formation of electroless Ni-B coatings using low temperature bath and evaluation of their characteristic properties, Surf. Coat. Technol. 200 (2006) 6888-6894.

[11]R. K. Roy, A Primer on the Taguchi Method, Society of Manufacturing Engineers: Dearborn. 1990.

[12]D. C. Montgomery, Design and Analysis of Experiments, John Wiley, New York. 2001.

[13] Minitab User Manual (Release 15.1) Making data analysis easier. State College (PA): MINITAB Inc.; 2001. 